\title{
Ciência, religião e Ilustração: as academias de ensino dos dissentes racionalistas ingleses no século XVIII*
}

Luiz Carlos Soares

Universidade Federal Fluminense

RESUMO

No século XVIII, as Academias Protestantes Dissidentes se constituíram no espaço privilegiado para o ensino das novas Ciências Naturais, na sociedade inglesa. Impossibilitados de ingressar no sistema de ensino fundamental e universitário inglês, controlado legalmente pelos Anglicanos, não restou aos Dissidentes ou Não-Conformistas outra alternativa que não fosse o estabelecimento de Academias de Ensino com o objetivo de preparar os jovens para ingressarem no ministério religioso, na vida universitária e nas atividades profissionais. Entre estas instituições se destacaram as Academias de Warrington e Manchester, sendo a primeira fundada pelos Presbiterianos (autodenominados Dissidentes Racionalistas) e a segunda pelos Unitários, herdeiros do Racionalismo Presbiteriano, mas distanciados da sua perspectiva teológica Calvinista.

Palavras-chave: dissidentes; racionalistas; Inglaterra.

\section{ABSTRACT}

The Academies of Prostestant Dissenters were the outstanding institutions for the teaching of new Natural Sciences in the eighteenth-century in the English society. As the Prostestant Dissenters were not allowed to enter in the English system of fundamental and university education, legally controlled by the Anglicans, there was no other alternative to them than the establishment of their Academies for Further Education in order to instruct their youth to the religious ministry, the university courses or the business life. The Academies of Warrington and Manchester were the most distinguished amongst these educational institutions, being respectively established by the Prebysterians (self-named the Rational Dissenters) and the Unitarians, the heirs of Prebysterian Rationalism although distanced of their Calvinist teological perspective. Keywords: dissenters; rationalism; England. 


\section{DO PRESBITERIANO AO UNITARISMO: A TRAJETÓRIA}

\section{DOS DISSIDENTES RACIONALISTAS INGLESES}

Os Protestantes Dissidentes ou Não-Conformistas eram homens profundamente ligados às várias correntes ou seitas protestantes Não-Anglicanas - Batistas, Anabatistas, Quakers, Presbiterianos (denominação dos Calvinistas na Inglaterra e na Escócia)), Independentes (também chamados Congregacionalistas) - que se constituíram no século XVI e, em meados do século XVII (1648-1660), promoveram a Revolução Puritana, que aboliu a monarquia e conduziu Oliver Cromwell ao poder. Logo em seguida à Restauração da Monarquia e da Dinastia Stuart, o rei Charles II iniciou um processo de perseguição aos Protestantes Não-Anglicanos com a aprovação, pelos seus aliados no Parlamento, do Corporation Act (Lei Corporativa) de 1661, que obrigava as autoridades civis das municipalidades (Borough Corporations) a adotarem os ritos religiosos e participarem dos serviços da Igreja Anglicana (Church of England). ${ }^{1}$

Em 1662, esta perseguição se aprofundou com a aprovação do Act of Uniformity (Lei da Uniformidade) pelo Parlamento, que procurava estabelecer uma padronização religiosa a partir do Anglicanismo e obrigava os Protestantes Não-Anglicanos a se conformarem aos fundamentos teológicos e ritos da religião oficial. Como os Protestantes Não-Anglicanos se recusaram a se submeter à padronização religiosa, passaram então a ser chamados de Dissidentes (Dissenters) ou Não-Conformistas (Non-Conformists). Por outro lado, isto significou a expulsão efetiva (Ejection) dos professores e alunos Dissidentes das tradicionais universidades inglesas, Oxford e Cambridge, e das escolas de ensino fundamental controladas pelo Oficialismo Anglicano. Mais de 2.000 párocos e vigários, muitos dos quais professores, foram excluídos de seus postos em virtude da Lei da Uniformidade, o que deu origem a um grande número de pequenas Academias de Ensino destinadas à educação dos Protestantes Não-Conformistas, que eram dirigidas por tutores individuais e caracterizavam-se pelo "nomadismo" constante, não se fixando em qualquer cidade por longo tempo.

Outras medidas de perseguição religiosa aos Protestantes Não-Conformistas ainda foram aprovadas pelo Parlamento. Em 1664, diante da evidência de reorganização dos Protestantes Não-Aglicanos, que procuravam retomar clandestinamente os seus cultos religiosos, aprovou-se o Conventicle Act (Lei dos Conventilhos), que proibiu a realização de reuniões religiosas com mais de cinco pessoas, que não obedecessem aos ritos da Igreja Anglicana. No ano seguinte (1665), o Parlamento instituiu o Five Mile Act (Lei das Cinco Milhas), que procurou proibir os religiosos Não- 
Conformistas de chegarem a menos de cinco milhas de qualquer cidade, sobretudo daquelas localidades em que desempenharam anteriormente $\mathrm{o}$ seu ministério religioso.

Em 1672, Charles II, com a Declaration of Indulgence (Declaração de Indulgência), ainda tentou relaxar a legislação contra os Não-Conformistas, mas isto provocou uma grande reação dos Anglicanos mais conservadores e ortodoxos, que também acusavam o monarca Stuart de ocultar a sua fé Católica. A reação do Parlamento contra os Dissidentes foi mais forte ainda e, em 1673, procurou-se excluir a presença deles, e também dos Católicos, das Forças Armadas, com a aprovação do primeiro Test Act (Lei do Teste), que impôs os testes religiosos para confirmação da fé Anglicana a todos aqueles que procuravam obter alguma patente militar na Marinha ou no Exército. Em 1678, o segundo Test Act estendeu a exclusão dos Dissidentes e Católicos à vida parlamentar, obrigando os membros de ambas as "Casas" do Parlamento (House of Lords e House of Commons) a responderem aos testes religiosos.

As duas grandes universidades controladas pelos Anglicanos também adotaram os Test Acts e submeteram os seus professores e, sobretudo, estudantes aos testes de comprovação de fé na Religião Oficial. Para ingressar em Oxford ou para se formar em Cambridge, os estudantes dos cursos de graduação tinham que subscrever os 39 artigos que faziam parte dos Test Acts. Na prática, a adoção desta lei significou a total exclusão dos Protestantes Dissidentes da vida universitária oficial da Inglaterra por quase dois séculos, embora o Toleration Act (Lei da Tolerância), de 1689, tenha revogado muitas das proibições impostas aos cultos Não-Conformistas.

Embora a suspensão da proibição aos cultos Não-Conformistas tenha durado cerca de um ano (1672-73), os Protestantes Dissidentes aproveitaram-se da situação para formar suas Congregações Religiosas por todo o país. Obviamente, com a revogação da Declaração de Indulgência, estas Congregações voltaram à clandestinidade e seus membros procuraram evitar a publicidade de suas atividades. James II, já no ocaso de seu reinado (1685-1688), procurou relaxar novamente as proibições aos Dissidentes com uma segunda Declaração de Indulgência, em 1687. Todavia, de nada valeu o esforço deste monarca - um aliado político do Partido Tory, representante do Anglicanismo mais conservador e ortodoxo -, que, com a Revolução Gloriosa (Glorius Revolution, 1688-1689), foi deposto pelas forças liberais do Parlamento - Partido Whig - e impedido de restaurar as velhas práticas absolutistas.

Com a Revolução Gloriosa e a instituição definitiva da Monarquia Cons- 
titucional Parlamentar, a tolerância religiosa foi colocada na ordem do dia, visto que o espírito liberal do novo regime, tendo à frente o rei William II, estabeleceu a liberdade de culto religioso para a grande maioria dos NãoConformistas, que teriam que obter, doravante, licença para garantir o funcionamento das suas "casas" religiosas. Embora a Lei da Tolerância tenha sido fruto da influência de uma nova Teologia Anglicana Latitudinária, que defendia a liberdade de opinião e de interpretação dos textos bíblicos e a reconciliação com os Não-Conformistas, o universo da liberdade religiosa ainda foi consideravelmente limitado, pois foi mantida a proibição formal para os Católicos Romanos e aqueles setores Dissidentes identificados com posições teológicas Anti-Trinitárias ou "Unitárias", que mais tarde se disseminariam no interior do Presbiterianismo.

No final do reinado da rainha Anne (1702-1714), os Protestantes Dissidentes voltaram novamente a ser perseguidos pelos Tories, que se tornaram a força majoritária no Parlamento. Aproveitando-se do ambiente político de tolerância anterior, muitos Dissidentes começaram a participar da vida política nas municipalidades, chegando a se utilizar, para isso, de um recurso previsto pelo Corporation Act (1661), que era a realização de uma comunhão obrigatória anual numa paróquia Anglicana. Com o 176 objetivo de conter a ascensão dos Não-Conformistas, a maioria Tory aprovou o Occasional Conformity Act (Lei da Conformidade Ocasional), em 1710, que na realidade procurou proibir o subterfúgio utilizado pelos Dissidentes para participarem da vida política. Os Tories ainda tentaram um golpe mais profundo sobre os Dissidentes com o Schism Act (Lei do Cisma) de 1714, que procurou impedi-los de ensinar em suas Escolas e Academias de Ensino, medida esta que equivalia ao fechamento destes estabelecimentos e ao fim da educação de sua juventude e de seus ministros religiosos.

Todavia, a morte da rainha Anne e a ascenção ao trono de George I, de Hanover, mudou completamente o panorama político inglês, ainda no ano de 1714, e estas últimas leis restritivas não foram colocadas em prática pelo novo Parlamento, dominado novamente pelas forças liberais. Por conta desta reviravolta política e do seu afastamento do poder, diversos setores do Partido Tory reataram a antiga aliança com os Stuart, através de James Francis Edward (filho de James II), pretendente ao trono britânico, e promoveram em 1715 a Primeira Revolta Jacobita (Jacobite, denominação desta aliança católico-conservadora), que foi derrotada. Esta derrota significou, para os Tories, um longo período de ostracismo na política britânica e a sua total exclusão da vida na Corte. Em 1745, os Jacobitas reeditaram a antiga aliança com os Stuarts, desta vez com Charles 
Edward (filho de James Francis Edward e neto de James II), e promoveram uma Segunda Revolta, que foi novamente derrotada pelas forças da ordem liberal.

Os Whigs, que foram fundamentais para o estabelecimento da Dinastia de Hanover, mantiveram uma longa e plena hegemonia na vida político-parlamentar durante os reinados de George I (1714-1727) e George II (1727-1760). Neste período, a tolerância aos Não-Conformistas se ampliou bastante e, embora sem a abolição formal de toda a legislação excludente, muitos deles, utilizando-se das brechas legais permitidas, puderam ingressar nas Forças Armadas, nas representações dos Conselhos Municipais e no próprio Parlamento, principalmente na Câmara dos Comuns. Nesta casa, os Protestantes Dissidentes que conseguiram ser eleitos como Members of Parliament (MPs, Membros do Parlamento) aliaramse naturalmente aos Anglicanos Liberais, que constituíam a base do Partido Whig, procurando defender a causa da liberdade política, civil e religiosa e se opor ao conservadorismo e à intolerância do Partido Tory, limitado à atuação oposicionista durante os reinados dos dois primeiros reis Hanoverianos. Somente no reinado de George III (1760-1820), por conta da própria luta interna no Partido Whig e da política de alianças do primeiroministro Pitt, o Moço, os representantes das antigas famílias Tories voltaram a participar do governo e a ter acesso novamente às atividades da Corte.

No início do século XVIII, de acordo com as estimativas do historiador Michael Watts a partir de um censo religioso de 1715, os Protestantes Dissidentes não ultrapassavam a $6 \%$ do conjunto da população da Inglaterra e do País de Gales, que ainda não tinha alcançado os seis milhões de habitantes. Segundo Watts, o número total de Dissidentes atingia a 338.210 pessoas, das quais pouco mais da metade era formada (3\%) pelos Presbiterianos e a outra metade pelas diversas denominações religiosas (Quakers, Batistas Particulares, Batistas Gerais e Independentes ou Congregacionalistas). As Congregações Dissidentes chegavam ao total de 1840, sendo 637 Presbiterianas, 672 Quakers, 206 Batistas Particulares, 122 Batistas Gerais e 203 Independentes. A maioria Presbiteriana era ainda mais expressiva em determinadas áreas do norte da Inglaterra, como Devon, Northumberland, Chesire e Lancashire, chegando nesta última a $8 \%$ da população. ${ }^{2}$

Obviamente, diversas eram as bases e as controvérsias teológicas entre as correntes Dissidentes. Todavia, estas não serão objeto deste artigo, que procurará focalizar um pouco mais a perspectiva religiosa dos Pres- 
biterianos no século XVIII, mais articulada com as manifestações da Filosofia das Luzes. Será destacado ainda o projeto Presbiteriano de estabelecimento de uma formação religiosa racional conjugada a um amplo processo de formação cultural, que priorizava a adoção de uma metodologia educacional voltada para a ampliação do horizonte intelectual dos seus ministros religiosos, e para a preparação adequada da sua juventude laica destinada às profissões letradas e às atividades comerciais, bancárias e industriais.

Os Presbiterianos, como defendiam de modo mais firme o princípio da "razão", além das liberdades civis e religiosas, podiam ser considerados, no século XVIII, como os autênticos Dissidentes Racionalistas, ao contrário dos "Protestantes Evangélicos" (os Batistas Gerais e Particulares e os Metodistas, surgidos na segunda metade do século XVIII) e de suas diversas "teorias" ("a corrupção total e inata ao gênero humano" e, por conseqüência, a "reprovação", a “expiação”). Em meados do século, pode-se dizer que as Congregações Presbiterianas se dividiam em dois grupos distintos: os Arianos e os Socinianos. ${ }^{3}$ Os primeiros, ainda no início do século, procuraram se distanciar da rígida doutrina Calvinista, adotando uma perspectiva teológica mais liberal em que a pessoa de Cristo, na hierarquia divina, era colocada numa posição abaixo do "Pai", mas ainda distinta e de maior importância do que a posição de todas as outras "criaturas”. Embora procurando se mover num universo teológico Trinitário, os Arianos estabeleceram uma ruptura na harmonia igualitária da Santíssima Trindade, que era aceita tanto pelo Anglicanismo Ortodoxo como pelo Catolicismo.

Pode-se dizer que a mudança de trajetória do Presbiterianismo inglês, com o surgimento do Arianismo, esteve muito articulada às novidades teológicas no interior do Anglicanismo, promovidas por alguns teólogos liberais e latitudinários, como Samuel Clarke, que em 1712 publicou o livro The scripture-doctrine of the Trinity (A doutrina biblica da Trindade). Nesta obra, Clarke praticamente formulou as bases de uma nova interpretação Trinitária que recuperava as antigas idéias do bispo Arius (século IV), e afirmava que o poder divino não se constituía de "três Pessoas eternas e em posição de igualdade, mas que o Deus Pai era supremo e Jesus, embora preexistente e divino, era subalterno". As idéias de Clarke tiveram um enorme impacto sobre os círculos Presbiterianos que já procuravam criticar aquelas correntes teológicas que se limitavam a uma visão literal e fundamentalista dos textos bíblicos. Com o Criticismo Bíblico instaurado no interior do Presbiterianismo, muitos ministros (em suas Congrega- 
ções) e tutores (em suas Academias de Ensino) adotaram entusiasticamente a nova interpretação Trinitária, que se transformou numa poderosa alavanca das transformações intelectuais na primeira metade do século XVIII.

Já os Socinianos, identificados com as propostas de uma Religião Natural ou Racional, bastante difundida em meados do século, defendiam mais claramente uma perspectiva teológica Anti-Trinitária ou Unitária, identificada com as idéias de Laelius e Faustus Socinus (teólogos do final do século XVI e início do XVII), que afirmavam a "unipersonalidade de Deus" e a "plena humanidade de Cristo". O Socinianismo também se espalhou pelas Congregações e Academias de Ensino, conjugado com uma maior radicalidade na defesa das liberdades civis e religiosas, mas não chegou a se transformar na corrente hegemônica dos Dissidentes Presbiterianos, muitos dos quais permaneceram fiéis à visão moderada Ariana até o final do século.

Entretanto, a partir dos anos 1750, a idéia de uma Religião Natural ou Racional foi difundida cada vez mais nas Congregações e Academias de Ensino Presbiterianas. Com isso as Teses Socinianas da "unipersonalidade de Deus" e da "plena humanidade de Cristo" puderam se combinar com a perspectiva ilustrada e antropocêntrica de uma religião "primária" e "universal" que "ligaria a humanidade a uma lei moral comum", proporcionada por um "Deus Benefactor" garantidor de uma "ordem natural harmoniosa" e do "bem estar do homem na sociedade". Com isso, o fenômeno da "revelação religiosa" não era necessariamente descartado, mas não podia ser resultado de um "dogma seletivo" ou da "superstição", que eram vistos como "as causas das guerras religiosas, das perseguições, da intolerância e do vício". A "revelação religiosa” tinha que se harmonizar com a Razão, a Consciência e o Conhecimento, considerados como componentes essenciais de uma "natureza humana universal". ${ }^{4}$

Desse modo, os Presbiterianos procuravam denunciar grande parte da trajetória do Cristianismo como uma "era de escuridão", dominada pelo dogma e pela superstição, e restaurar a sua honra como uma Religião Natural e Racional, na nova "era de retorno das luzes”. Embora o grande nome da Teologia Racional, na segunda metade do século XVIII, fosse o dr. Joseph Priestley, é num texto do dr. Thomas Barnes, de 1786, que podemos encontrar uma das melhores sínteses acerca da nova perspectiva de religiosidade que surgiu nos círculos Presbiterianos. No melhor estilo de um pregador religioso, numa passagem (de frases curtas e incisivas) que fornece elementos justificativos para um Cristianismo Ilustrado e 
Racional e para a demonstração da compatibilidade entre Ciência e Religião, Thomas Barnes afirmava:

A verdade divina não procura ocultamento. Ela não teme a descoberta. $\mathrm{O}$ conhecimento sadio, de qualquer espécie, definitivamente deve ser seu amigo. E ela prevalecerá. Agora mesmo, ela está prevalecendo rapidamente. O dia já está clareando. A luz do céu está avançando. As faculdades humanas estão em movimento. A Religião do Novo Testamento, que, como uma imensa montanha, foi obscurecida por longo tempo pela neblina, agora levanta seu majestoso topo, e sob a providência de seu Criador, elevar-se-á mais alto do que aquelas nuvens, que têm obscurecido a sua glória. ${ }^{5}$

Por outro lado, de nada adiantaria este combate à superstição e à ignorância, se a "Religião Divina" não afirmasse os princípios da tolerância e da liberdade civil e religiosa. Assim, o dr. Thomas Barnes complementava:

Unir a humanidade, não pelos laços da ignorância e da hipocrisia, mas pelo cimento de um amor ilustrado e difuso, este é o espírito desta Religião $D i$ vina, da qual nos orgulhamos; esta é a tendência daqueles princípios pelos quais nos distinguimos, [...] a causa da Liberdade Civil e Religiosa. Entre todos os homens, e por todos os meios, o espírito da liberdade, da tolerância, e de candura, e em conexão com ele, o espírito de virtude e religião, são difundidos; e isso consideramos como o triunfo de nosso interesse. ${ }^{6}$

Na realidade, a perspectiva teológica defendida por Barnes já se situava claramente num quadro de desdobramento e ruptura em relação às Teses Socinianas. Isto porque muitos Socinianos, adeptos de uma perspectiva ilustrada mais radical, não viam nenhuma necessidade de se manterem ainda vinculados a uma tradição Calvinista ascética e pietista. Esta ruptura se manifestou nos anos 1770, com o nascimento do Unitarismo que assumiu abertamente a religiosidade naturalista da Ilustração, e procurou defender com radicalidade a causa da liberdade civil e religiosa, sendo que os setores mais extremados admitiam mesmo a possibilidade de uma revolução democrática para atingi-la. Deste modo, os Unitários aproximaram-se dos princípios revolucionários surgidos na França e constituíram-se, por isso, nos arautos do Radicalismo ou Liberalismo Democrático britânico, do final do século XVIII e da primeira metade do século XIX. Além da unidade de Deus e do Anti-Trinitarismo, os Unitários negavam enfaticamente que a morte de Cristo fosse um sacrifício ou uma expiação em virtude dos pecados da humanidade, o que fez com que muitos dos seus opo- 
sitores, conservadores e moderados, passassem a acusá-los de Anticristãos e, mesmo, de materialistas.

É interessante notar que, embora grande parte da base Unitária tenha vindo das fileiras Socinianas do Presbiterianismo, esta nova corrente religiosa também foi adotada por muitos Anglicanos Liberais e Batistas Gerais, também adeptos de uma religiosidade ilustrada, que se distanciaram da tradição Trinitária. Embora o Unitarismo fosse considerado ilegal pelas disposições do Toleration Act, uma primeira capela Unitária foi aberta em Londres, em 1774, por Theophilus Lindsey, que era amigo e colaborador de Joseph Priestley. Lindsey fazia parte, anteriormente, de um grupo de religiosos Liberais Anglicanos que defendiam a abolição da subscrição aos 39 artigos dos Test Acts para os Não-Conformistas. Todavia, entrou em rota de choque com o Anglicanismo quando, em 1772, o Parlamento rejeitou um projeto de lei, resultante de uma ampla campanha de assinaturas - a Feathers Tavern Petition (Petição da Taverna Feathers) -, para liberar os Dissidentes da subscrição requerida.

Uma outra conversão importante ao Unitarismo foi a de Thomas Belsham, que era tutor e diretor da Academia de Daventry. Em 1789, Belsham anunciou a sua ruptura com o Calvinismo e a adoção do Unitarismo, com fortes críticas à tradição Presbiteriana e à defesa do ensino sistemático da Filosofia Necessária (Necessarian Philosophy) celebrada por Joseph Priestley. Nos anos 1780, o impacto da conversão de Belsham estimulou a adoção da perspectiva Unitária em diversas Congregações e Academias de Ensino, principalmente entre os jovens tutores e estudantes, e também contribuiu para transformar as idéias de Priestley na base filosófica da Teologia Unitária inglesa do final do século XVIII e da primeira metade do século XIX.

$\mathrm{Na}$ sua mais importante obra de crítica e exegese bíblicas, History of the corruptions of Christianity (História das Corrupções da Cristandade), de 1782, Priestley afirmava que nos primeiros séculos da Igreja, o Cristianismo era fundamentalmente Unitário e que, sob a "maligna influência do pensamento grego", iniciou sua trajetória de "infeliz decadência” em direção ao "mistério e obscurantismo". As bases filosóficas de Priestley repousavam na "Psicologia da Mente" de John Lock e nas teses do médico e psicólogo David Hartley, publicadas em 1748 no livro Observations on man. O próprio Priestley se considerava muito mais um "transmissor e popularizador" das teses de Hartley do que um "filósofo original” ou criador de um "novo sistema filosófico".

Para os historiadores Jean Raymond e John Pickstone, o nome de 
Joseph Priestley não pode ser dissociado das figuras exponenciais da Ciência britânica da segunda metade do século XVIII. Priestley foi não apenas "a figura-chave e o herói radical dos Unitários da Inglaterra industrial", como também "o expoente de uma rigorosa filosofia necessária; um gigante da química pneumática; um pioneiro da história como disciplina, especialmente da história da ciência”. Em seus muitos trabalhos publicados, em sua atividade como professor e em seu ministério religioso, Priestley procurou, de acordo com Raymond e Pickstone, "construir e propagar uma filosofia na qual o progresso das ciências naturais era a evidência central do desdobramento do propósito divino”. Ainda sobre a Filosofia Necessária, os dois historiadores afirmam que "Priestley e seus muitos seguidores pregaram um credo baseado numa explicação materialista do homem", no qual a natureza era vista como "um sistema infinito de causas interligadas, criado por Deus".?

Os adeptos radicais do Liberalismo, em particular os Unitários, sofreriam grande perseguição nos anos 1790, na medida em que suas idéias eram identificadas, pelos setores mais conservadores da sociedade inglesa, com o ideário do Jacobinismo francês e sua perspectiva claramente republicana e contrária à religiosidade Cristã tradicional. Antes mesmo 182 da instalação da hegemonia Jacobina, durante a Convenção (1792-1795), as forças conservadoras da Inglaterra procuraram frear o crescimento do Radicalismo Liberal, que tinha os Unitários como o seu setor de vanguarda, e esta tentativa se manifestou com as King and God Riots (Revoltas de Deus e do rei) que ocorreram em diversas cidades no início dos anos 1790, mas atingiram a maior intensidade em Birmingham em 1791. Durante três dias (14 a 17 de julho), nesta cidade, uma multidão enfurecida investiu contra duas capelas (Old Meeting e New Meeting), residências e propriedades dos Unitários e daqueles próximos a eles, gritando o nome do rei e de Deus, destruindo praticamente tudo o que via pela frente. Os revoltosos procuraram atingir justamente o maior nome do Radicalismo inglês, Joseph Priestley, que teve sua casa invadida e incendiada, com a destruição de sua biblioteca e laboratório. Depois disso, Priestley abandonou Birmingham e se tornou ministro na Capela de Gravel-pit, em Hackney, próximo de Londres, lecionando também na Academia Dissidente da mesma localidade. Em 1794, sentindo-se ainda ameaçado, Priestley abandonou a Inglaterra e foi viver nos Estados Unidos, instalando-se na cidade de Northumberland, Pensilvânia, onde passou os últimos dez anos de sua vida.

Diante da reação conservadora, fortalecida mais ainda pela declara- 
ção de guerra à França revolucionária (1792) pelo governo liberal pragmático do primeiro ministro Pitt, o Moço, o Radicalismo inglês e o movimento Unitário sofreram um terrível golpe, com a desmobilização de suas bases em virtude da existência de um clima político de perseguição. No mesmo momento, as bandeiras das reformas, "dentro da lei e da ordem”, passaram às mãos das correntes Evangélicas, revigoradas com a expansão do Metodismo de John Wesley. Na década final do século XVIII e na década inicial do século XIX, oradores do porte de Thomas Clarkson e William Wilberforce reuniam multidões na sua pregação contra o tráfico de escravos africanos e os vícios da "aristocracia" e da "plebe" (alcoolismo, promiscuidade sexual, esportes cruéis, etc.), antecipando um quadro de moralidade religiosa burguesa (middle class morality) que se fortaleceria no decorrer do século XIX. Neste contexto, não restou aos Liberais Radicais e aos Unitários outra alternativa que não fosse o redirecionamento de seu discurso político e de suas estratégias de atuação, procurando adequar-se à legalidade, e até mesmo adotando uma "perspectiva patriótica” diante da continuidade da guerra com a França, intensificada no período Napoleônico.

Esta mudança de trajetória política proporcionou uma primeira vitória aos Unitários, que foi a aprovação pelo Parlamento do Trinity Act (Ato Trinitário) de 1813, que tornou sem efeito algumas leis restritivas do século XVII, legalizando assim o pensamento Unitário e a prática religiosa de seus adeptos. A esta altura, as antigas Congregações Presbiterianas já tinham desaparecido do cenário inglês, pois muitas delas não conseguiram resistir à força dos argumentos do Racionalismo Unitário na sua contundente rejeição às teses Arianas e à tradição Calvinista. As Comunidades Presbiterianas se desintegraram e a grande maioria de seus membros aderiu ao Unitarismo. Esta corrente religiosa herdou, assim, toda a tradição do Racionalismo Dissidente e se constituiu numa "elite intelectual", como assinalou o historiador Asa Briggs, que, além de seu projeto educacional, teve uma enorme participação na vida política local e nacional da Inglaterra, na primeira metade do século XIX. ${ }^{8}$

\section{AS ACADEMIAS DISSIDENTES PRESBITERIANAS \\ NA PRIMEIRA METADE DO SÉCULO XVIII}

No século XVIII, as Academias Protestantes Dissidentes se constituíram no espaço privilegiado para o ensino das novas Ciências Racionalistas e Experimentais, na sociedade inglesa. Impossibilitados de ingressar no sistema de ensino fundamental e universitário inglês (Universidades de Oxford e Cam- 
bridge), controlado legalmente pelos Anglicanos desde a época da Restauração Stuart (1661-1688), não restou aos Protestantes Dissidentes ou NãoConformistas outra alternativa que não fosse o estabelecimento de Academias de Ensino com o objetivo de preparar os jovens para ingressar no ministério religioso, nos diversos cursos universitários e nas atividades vinculadas ao comércio, bancos e indústrias. ${ }^{9}$

Entre estas academias se destacaram aquelas criadas pelos Presbiterianos que, durante o século XVIII, autodenominaram-se "Protestantes Racionais" e estimularam o ensino das novas Ciências Naturais, ainda sob o antiga denominação de "Filosofia Natural". As Academias dos Dissidentes Presbiterianos também se constituíram em importantes espaços de combate à intolerância e às exclusões impostas pelo Anglicanismo dominante e, ainda, de defesa intransigente da liberdade civil e religiosa, no melhor estilo dos ideais da Ilustração setecentista. Entre as instituições de ensino, sobressaíram-se a Academia de Warrington (1757-83) e a Academia de Manchester (1786-1803), que se tornaram referências importantes para um novo tipo de ensino, voltado especialmente para as Ciências Naturais e Experimentais, e para sua aplicação prática às necessidades da população de um país que assistia aos primeiros passos da grande trans184 formação técnico-produtiva, que se constituiu na Revolução Industrial.

A partir dos anos 1690, com a política de tolerância religiosa estabelecida pela Revolução Gloriosa (1688-1689), as Academias Dissidentes de Ensino passaram a ter mais regularidade nas suas atividades, além da possibilidade de se fixarem nas cidades escolhidas pelos seus tutores. Inclusive, muitas novas academias chegaram a se estabelecer nos 30 anos seguintes à Revolução Gloriosa. As academias dirigidas especialmente por tutores Presbiterianos procuraram romper com a tradição clássica e escolástica adotada nas Academias Dissidentes criadas antes da Revolução, que enfatizava o ensino de Teologia, Metafísica e Ética e em nada se diferia do modelo de ensino de Oxford e Cambridge. Nas Academias Presbiterianas, o ensino de Matemática e Filosofia Natural (Física, Astronomia e Química) passou a ter um papel mais destacado como elemento de "prova da Religião Natural", o que significava a adoção plena de uma perspectiva de Cristianismo Racional ou Religião Racional que tanto distinguiu esta corrente religiosa no decorrer do Século das Luzes.

De acordo com o historiador Herbert McLachlan, as Academias de Ensino Presbiterianas se destacaram pela introdução não somente de "assuntos modernos", como também de um "currículo mais amplo" que, no século XVIII, possibilitou a formação para alguns dos primeiros cien- 
tistas e filósofos da Europa”. ${ }^{10}$ Além disso, estas Academias de Ensino já começavam a estabelecer uma tradição que iria ser, no decorrer do século, um outro fator de distinção dos Presbiterianos, na sua luta pelas liberdades religiosas e civis e contra a intolerância do Conservadorismo Anglicano, que era, como lembram Jean Raymond e John Pickestone, o seu regime de admissão "livre de quaisquer testes religiosos" para que seus estudantes melhor pudessem se dedicar à "busca da razão em todos os campos do conhecimento humano". Desse modo, a Filosofia Natural ou as modernas Ciências Naturais se tornaram não apenas a base para um "Conhecimento Racional", como também o "paradigma da livre investigação", na opinião desses dois historiadores. ${ }^{11}$

Em geral, já no início do século XVIII, os Protestantes Dissidentes e os Anglicanos Liberais baseavam-se nos currículos destas Academias de Ensino para direcionar as suas pesadas críticas contra o que eles chamavam de um "currículo arcaico" adotado pelas Universidades de Oxford e Cambridge, nas palavras de Ruth Watts, "adequado para o século dezesseis, mas anacrônico em tempos mais científicos e modernos". Os críticos do sistema universitário oficial também não poupavam suas outras mazelas, que na sua opinião eram a exclusividade para os Anglicanos (através da subscrição aos 39 artigos de fé), o alto custo para a realização dos seus cursos e o "espírito aristocrático e licencioso das universidades", como assinala a historiadora supramencionada. ${ }^{12}$ Herbert McLachlan (que publicou seus trabalhos nos anos 1940) lembra ainda que o "veredito" dos historiadores e estudiosos dos problemas educacionais britânicos tem sido de que as duas grandes universidades inglesas, durante o século XVIII e boa parte do século XIX, "estavam geralmente num estado de repouso, para não dizer coma, não incomodadas pelo novo e vigoroso pensamento de homens conscientes dos problemas que tinham que enfrentar acerca da religião e política, indústria e comércio". ${ }^{13}$

Esta também tem sido a opinião de historiadores da nossa época, como Eric Hobsbawm, que se utiliza dos termos: "piada de mau gosto", para caracterizar o estado geral da educação inglesa, e "intelectualmente nulas”, para a situação particular de Oxford e Cambridge no século XVIII. Assim, manifesta-se Hobsbawm:

A educação inglesa era uma piada de mau gosto, embora suas deficiências fossem um tanto compensadas pelas duras escolas do interior e pelas universidades democráticas, turbulentas e austeras da Escócia Calvinista, que lançavam uma corrente de jovens racionalistas, brilhantes e trabalhadores, em busca de uma carreira no sul do país: James Watt, Thomas Telford, Lou- 
don McAdam, James Mill. Oxford e Cambridge, as duas únicas universidades inglesas, eram intelectualmente nulas, como o eram também as sonolentas escolas públicas, com exceção das Academias fundadas pelos dissidentes que foram excluídas do sistema educacional (anglicano). Até mesmo as famílias aristocráticas que desejavam educação para seus filhos confiavam em tutores e universidades escocesas. ${ }^{14}$

Ruth Watts nos fornece uma interessante descrição da situação das Universidades de Oxford e Cambridge, durante todo o século XVIII e início do século XIX. De acordo com esta historiadora, "embora existisse uma diversidade de cátedras universitárias”, as duas universidades "eram, de fato, dominadas por colégios ricos e indolentes que se concentravam num leque estreito de disciplinas, uma limitação que era exacerbada pelo crescimento de exames compulsórios”. Além disso, estas instituições ofereciam um ensino de características "predominantemente clericais", desvinculado das preocupações filosóficas e científicas das mentes mais modernas:

Oxford se concentrava quase exclusivamente nos clássicos e em teologia, embora mesmo nestas áreas os grandes avanços alemães em crítica histórica e filologia eram todos ignorados, exceto por um punhado de acadêmicos dos anos 1820. Cambridge se tornou famosa por seus prestigiosos cursos triplos em matemática e física teórica, mas apesar de alguns excepcionais matemáticos reformistas, o curso, como o triplo clássico de 1822, era um isolado e altamente especializado treinamento em raciocínio para futuros advogados e homens de estado e não um moderno treinamento para matemáticos e cientistas profissionais. ${ }^{15}$

Todavia, os defensores do Ensino Oficial Anglicano não permaneceram calados diante das críticas dos que defendiam um "Sistema Liberal" de educação. Para os defensores do Oficialismo, o termo "liberal” significava, sobretudo, um tipo de ensino altamente "fragmentado" e "especializado", contrário ao "universalismo" das tradições culturais da upper class (classe alta), formada pela antiga aristocracia territorial e burgueses enriquecidos no comércio e na atividade bancária que adotavam os valores aristocráticos. De acordo com estes setores conservadores, o "Ensino Liberal" significava ainda a possibilidade de difusão de uma série de heresias religiosas, principalmente aquelas que procuravam contestar o Trinitarismo Anglicano.

Por volta de 1720, existiam cerca de 42 Academias de Ensino ou "Seminários” mantidos pelos Protestantes Dissidentes, espalhados pela In- 
glaterra, para garantir a formação dos seus quadros religiosos e a educação da sua juventude laica. Estas academias ainda eram dirigidas por tutores individuais, que algumas vezes tinham a necessidade de empregar subtutores que os auxiliavam nas atividades de ensino. Algumas das mais importantes academias localizavam-se no norte do país, e entre elas estavam as de Frankland, Sheffield, Benyon, Coningham, Dixon, Jollie, Owen, Whitehaven-Bolton, Attercliffe-Sheffield, Northampton, Kendal e Findern-Derby. Até os anos 1740, as Academias Dissidentes viveram uma situação de relativa "estabilidade" que era garantida, principalmente, pelo apoio dos Fundos Religiosos (Denominational Funds) existentes e dos novos fundos criados na época, tais como o Coward Trustees e a King's Head Society. Além de apoiarem os estudantes de Teologia, que tinham todas as suas taxas e despesas nas academias cobertas pelos fundos, estas instituições ainda podiam ajudar os estabelecimentos de ensino que enfrentavam eventuais dificuldades financeiras. A grande maioria dos estudantes destas academias era composta por alunos leigos, cujas famílias tinham que arcar com o pagamento das taxas cobradas pelos tutores e as despesas com acomodação e alimentação, caso não fossem das cidades onde se localizavam os estabelecimentos.

Entretanto, no início dos anos 1750, a situação financeira das Academias Dissidentes já não apresentava mais a estabilidade das décadas anteriores, e algumas delas chegaram mesmo a enfrentar um processo de "declínio gradativo", que levou ao seu fechamento. Além de problemas financeiros, um outro fator mencionado pelo reverendo William Turner para o fechamento de academias, em meados do século XVIII, foi o falecimento ou a aposentadoria de muitos renomados tutores, pois nem sempre os seus substitutos (muitos jovens e em início de carreira) apresentavam a mesma qualidade de trabalho e a formação educacional e teológica aprofundada dos seus antecessores. Isto, de acordo ainda com Turner, deixou a Comunidade Dissidente do norte da Inglaterra completamente "alarmada" e temendo pela continuidade da formação de sua juventude e pela preservação das suas próprias crenças religiosas. ${ }^{16}$

Algumas importantes academias deixaram de existir antes mesmo de meados do século XVIII, e entre elas estavam as de Whitehaven-Bolton (fechada em 1729) e Attercliffe-Sheffield (fechada em 1734). No início dos anos 1750, foi a vez das academias de Northampton (em 1751), Kendal (em 1753) e Findern-Derby (em 1754) fecharem as suas portas. Segundo Herbert McLachlan, com exceção da academia de Attercliffe-Sheffield, todas as outras ficaram famosas pelas suas "opiniões teológicas liberais". 
Obviamente, o fechamento das três últimas no início dos anos 1750 causou muito mais preocupação entre os Não-Conformistas porque os seus tutores não somente defendiam competentemente uma Teologia Liberal, como também eram reconhecidos entre os mais capazes educadores da Comunidade Dissidente, inclusive muito respeitados nos meios Anglicanos. O primeiro deles era o dr. Philip Doddridge, um ministro Congregacionista falecido em 1751, e cuja academia funcionou em Northampton desde 1729. O segundo era o dr. Caleb Rotherham, um ministro Presbiteriano falecido também em 1753, que dirigiu a Academia de Kendal. Por fim, o dr. Latham, ministro também Presbiteriano que faleceu em 1754, responsável pela Academia de Findern-Derby. ${ }^{17}$

A Academia de Northampton parece ter sido a mais renomada entre as instituições de ensino Não-Conformista da primeira metade do século XVIII. Sua fama foi criada pela reconhecida competência do dr. Philipe Doddridge, que ensinava a seus alunos somente na língua inglesa, o que segundo R. K. Webb, "levava a um enfraquecimento do estudo linguístico mas que também facilitava a leitura e a discussão de trabalhos modernos acerca de todos os assuntos". A característica mais extraordinária do método do dr. Doddridge, assinalada por R. K. Webb, era "sua insistência na exposição dos estudantes a todos os lados de todas as questões", através da leitura e do debate das obras de "autoridades rivais" (autores com pontos de vista contraditórios), o que os obrigava a desenvolver o seu próprio raciocínio e a ter a sua própria opinião, "na sala de aula e no mundo exterior a ela". Embora em outras academias da época este método fosse também utilizado, foi em Northampton que ele obteve maior notoriedade em virtude do trabalho do seu respeitado tutor. ${ }^{18}$

Com a morte do dr. Doddridge, houve iniciativas entre os Dissidentes para que não houvesse o fechamento da Academia de Northampton, assumindo um novo tutor, o dr. Caleb Ashworth. Entretanto, uma das primeiras medidas do novo tutor, quando da reabertura da academia em 1752, foi a sua transferência para a cidade de Daventry. O primeiro aluno a se matricular em Daventry foi Joseph Priestley, que iniciava assim com o dr. Ashworth a sua formação intelectual e religiosa, que o conduziria, durante os seus estudos (1752-1755), primeiramente para o campo teológico do Arianismo. A nova Academia de Daventry não foi suficiente para reduzir as preocupações dos Dissidentes com a formação dos seus filhos. Muitos, inclusive, parecem ter demonstrado um certo ceticismo, pois o dr. Ashworth estava em início de carreira e ainda não tinha o seu talento reconhecido pela Comunidade Dissidente, como aconteceria pos- 
teriormente. Portanto, a situação da academia era de instabilidade e continuaram os esforços desta comunidade, principalmente entre os Presbiterianos, para se chegar a uma solução mais duradoura.

Embora as Academias Dissidentes já tivessem o seu trabalho reconhecido, na realidade o significado de sua proposta de "educação avançada” não podia ultrapassar a formação dos ministros religiosos (Divines), a educação dos jovens destinados ao "mundo dos negócios" (comércio, bancos e indústrias), e a preparação daqueles que queriam ingressar nas "profissões eruditas" (os cursos universitários de Medicina, Direito, Filosofia, Letras e Literatura). Em geral, a duração dos estudos daqueles que queriam se dedicar à vida religiosa (Divinity Studies) era de cinco anos, enquanto os alunos que seguiriam as "profissões leigas" não passavam mais de três anos nas academias. Por outro lado, aqueles jovens Dissidentes que queriam seguir as "profissões eruditas”, impossibilitados de ingressar em Oxford e Cambridge, não tinham outra alternativa senão matricular-se nas Universidades da Escócia - Edimburgo, Glasgow ou Aberdeen. Não era raro também que estes jovens procurassem as Universidades Calvinistas da Holanda, principalmente a de Leyden, ou então as da Alemanha Luterana. Alguns Fundos Religiosos, como o Presbyterian Fund e o Dr. Williams's Trust, mandavam freqüentemente os melhores estudantes para as universidades escocesas, para pelo menos um ou dois anos de estudos.

Desde o século XVII, as universidades da Escócia Presbiteriana atraíram a atenção dos Dissidentes ingleses, sobretudo aqueles que viviam no Norte, em virtude da proximidade geográfica e das afinidades religiosas. Evidentemente, estas afinidades eram maiores para os Dissidentes Presbiterianos que tinham a mesma base de formação Calvinista dos escoceses. Em meados do século XVIII, esta atração se tornou ainda maior por conta dos renomados professores de Glasgow e Edimburgo, que distinguiam o movimento Ilustrado escocês como um dos mais criativos e respeitados na Europa das Luzes. O epicentro da Ilustração escocesa era o Glasgow College (Colégio de Glasgow), onde, segundo o Reverendo Turner, "a filosofia alcançou o primeiro nível, tendo sido ensinada por homens de grandes habilidades desde o início deste século" (XVIII). ${ }^{19}$

Era no campo da Filosofia Moral que o Glasgow College se distinguia, tendo ocupado esta cadeira quatro dos maiores representantes da Ilustração escocesa: Francis Hutcheson, Adam Smith, Thomas Reid e Dugald Stewart. A Filosofia Moral escocesa possibilitou não apenas o surgimento da "nova ciência da economia política", como também a vigorosa interpretação filosófica de Francis Hutcheson, na realidade um Presbiteria- 
no norte-irlandês, que deixou uma academia em Dublin, a partir de um convite recebido para lecionar Filosofia no Glasgow College. De acordo com McLachlan, Hutcheson foi "o primeiro a fixar o exemplo do uso regular do inglês ao invés do latim nas aulas”, exemplo que foi seguido pelo seu amigo Wiliam Leechman, responsável pela cadeira de Teologia no mesmo College. Por sua vez, Leechman também foi um inovador na área da Teologia, e suas aulas atraíam um grande número de estudantes oriundos da própria Escócia, da Inglaterra e da Irlanda. A Filosofia Moral de Hutcheson e a Teologia de Leechman, enfatizando a perspectiva racionalista das Luzes, tiveram grande influência, através dos seus alunos, sobre as Academias Não-Conformistas inglesas, a partir de meados do século XVIII, e foram, nas palavras de James Martineau, um importante fator de "relaxamento do Calvinismo severo", além de darem "um tom liberal para uma ampla minoria, dentro e fora da universidade”. ${ }^{20}$

\section{AS ACADEMIAS DE WARRINGTON E MANCHESTER: \\ O ENSINO DAS CIÊNCIAS NATURAIS}

Se na primeira metade do século XVIII algumas academias de ensino Não- Conformistas, sobretudo Presbiterianas, chegaram a ter um padrão de ensino universitário, com um currículo mais adaptado às necessidades da época e incluindo os objetos mais importantes das modernas Ciências, na segunda metade desse século esta orientação educacional se consolidou e contribuiu para a distinção de estabelecimentos como a Academia de Warrington (Warrington Academy) e a Academia de Manchester (Manchester Academy), que escreveram seus nomes na trajetória de renovação da educação inglesa. Em Warrington e Manchester chegaram a ensinar, respectivamente, Joseph Priestley e John Dalton, cientistas de grande reputação na segunda metade do século XVIII e início do XIX. ${ }^{21}$

$\mathrm{Na}$ realidade, as Academias de Warrington e Manchester foram herdeiras de importantes instituições de ensino Presbiterianas do norte da Inglaterra, tais como as Academias de Whitehaven-Bolton, Attercliffe (Sheffield), Kendal e Findern (Derbyshire), que, na primeira metade do século, já se notabilizavam por uma concepção de ensino inovadora e uma perspectiva teológica e religiosa racionalista e mais liberal. Todavia, com o fechamento destas instituições de ensino, setores importantes da Comunidade Presbiteriana nortista sentiram a necessidade da criação de uma nova instituição que, para evitar problemas como o falecimento do tutor, não fosse "propriedade" de um único indivíduo e tivesse a importante tarefa de formação intelectual dos jovens Dissidentes Racionalistas 
e dos seus futuros ministros religiosos, com base numa filosofia que defendia a igualdade de direitos civis e a liberdade religiosa e de pensamento.

A atuação do reverendo John Seddon foi fundamental para que se criasse, em 1757, na cidade de Warrington (quase a meio caminho entre Manchester e Liverpool, às margens do rio Mersey), uma nova academia com recursos oriundos das subscrições obtidas na própria Comunidade Dissidente, sobretudo Presbiteriana. Foi John Seddon quem organizou as primeiras reuniões entre os Presbiterianos com maior potencial para financiar as atividades da nova academia, que se tornaram seus subscritores anuais ("Trustees") e, logo, foi constituído o Conselho de Diretores da instituição. Por este esforço, o reverendo Seddon foi apontado, pelo Conselho Diretor, como o secretário da academia, sendo Arthur Heywood (de uma família de comerciantes e banqueiros de Liverpool) indicado seu tesoureiro e o $15^{\circ}$. barão de Parham, lorde Hugh Willoughby, que era o último representante das famílias aristocráticas Presbiterianas, escolhido como seu primeiro presidente. Lord Willoughby também era, na ocasião, vice-presidente da Royal Society of London e vice-presidente da Society for the Encouragement of Arts (Sociedade para o Incentivo às Artes). Posteriormente, em 1767, o reverendo Seddon, em reconhecimento pelo seu trabalho, foi apontado pelo Conselho Diretor como Rector Academiae (reitor da Academia), cargo este que conservou até a sua morte (1770), sendo substituído pelo dr. William Enfield.

Os primeiros tutores da academia foram os professores John Taylor (doutor em Teologia pela Universidade de Glasgow) e John Aikin (doutor em Teologia pela Universidade de Abeerden), evidenciando claramente o forte elo de ligação da intelectualidade Presbiteriana com as universidades da Escócia e os principais nomes do movimento iluminista escocês. O próprio secretário, John Seddon, mesmo sem uma trajetória intelectual tão brilhante como a dos dois primeiros tutores, como aluno da Universidade de Glasgow, teve uma enorme influência dos filósofos Hutcheson e Leechman. Mais tarde, com a ampliação da academia, foram incorporados outros tutores, como Joseph Priestley e William Enfield, que obtiveram seus títulos de doutorado na Universidade de Edimburgo.

Segundo as próprias palavras do secretário da Academia de Warrington, o principal objetivo educacional desta instituição era "implementar o progresso da verdadeira religião e a liberdade religiosa" ${ }^{22}$, mas foi um de seus primeiros tutores, o dr. John Taylor, com o seu livro-texto Scheme of Scripture Divinity (Esquema da Teologia das Escrituras), quem melhor divul- 
gou a filosofia educacional da instituição, baseada claramente no ideário Whig e nos princípios do Liberalismo Democrático nascente. Inicialmente, este livro foi preparado pelo dr. Taylor para o uso exclusivo dos alunos de Warrington, mas publicado comercialmente depois da sua morte, tendo como conteúdo os diversos assuntos explorados nas suas aulas de Teologia. Estas aulas eram prefaciadas pelo dr. Taylor, com uma espécie de "encargo solene" aos seus alunos, em que os princípios da liberdade religiosa, da liberdade de pensamento, da valorização da razão e da igualdade de direitos eram plenamente afirmados:

Eu solenemente vos encarrego, em nome do Deus da Verdade, e de Nosso Senhor Jesus Cristo, que é o caminho, a verdade e a vida, e diante de cujo juízo, vós deveis mostrar, sem nenhuma demora, $1^{\circ}$.) que em todos os vossos estudos e indagações de natureza religiosa, presentes ou futuros, vós dareis constantemente, cuidadosamente, imparcialmente e conscientemente atenção à evidência, como está nas sagradas escrituras, ou na natureza das coisas, e nos ditados da razão; prudentemente protegidos contra as investidas da imaginação, e da falácia da mal-fundamentada conjectura. $2^{\circ}$.) Que vós não admitireis, abraçareis e consentireis nenhum princípio ou juízo, por mim ensinado ou adiantado, exceto quando, na vossa opinião, ele se mostrar apoiado e justificado pela própria evidência da revelação, ou pela razão das coisas. $3^{\circ}$.) Que se, futuramente, algum princípio ou juízo por mim ensinado ou adiantado, ou por vós admitido ou abraçado, que, na vossa opinião, mostrar-se dúbio ou falso, a partir de um exame imparcial e fiel, vós devereis suspeitar ou rejeitar totalmente tal princípio ou juízo. $4^{\circ}$.) Que vós mantereis vossas mentes sempre abertas à evidência; que vós vos esforçareis para banir de vossos sentimentos todo o preconceito, prepotência, e partidarismo; que vós estudareis para viver em paz e amor com vossos semelhantes cristãos; e que vós sustentareis firmemente para vós mesmos, e livremente permitireis para outros, os direitos inalienáveis de opinião e consciência. ${ }^{23}$

De acordo com o Plano de Educação da Academia de Warrington, o "curso completo", destinado àqueles que pretendiam exercer o ministério religioso, tinha uma duração de cinco anos, mas existia um "curso especial", com a duração de três anos, para os jovens que "aspiravam por uma vida de Negócio ou Comércio". A grande maioria dos estudantes começava a cursar a academia com a idade de 14 anos e tinha uma clara preferência pelo curso de três anos, que servia como uma excelente preparação para a entrada nos diversos cursos das universidades escocesas, da Universidade de Leyden (Holanda) e, em pouquíssimos casos, das universidades Anglicanas (Cambridge e Oxford). Para o curso de três anos, 
o Plano de Educação de Warrington estabelecia as seguintes disciplinas e atividades:

\section{Primeiro Ano:}

1) Matemática Elementar (Aritmética, Álgebra e Geometria). 2) Francês. 3) Gramática Universal e Retórica. Exercícios Semanais: 1) Tradução do Francês para Inglês. 2) Composição de um ensaio sobre um assunto em Inglês. 3) Reprodução de diversos tipos de cartas no estilo epistolar.

\section{Segundo Ano:}

1) Matemática (Trigonometria; Navegação, se desejada). 2) Filosofia Natural, e 'as partes mais fáceis da Astronomia aplicada para o uso de Globos e o sistema geral do Universo’. 3) Francês. Exercícios Semanais: 1) Tradução do Inglês para o Francês. 2) Reprodução de diversos tipos de cartas em Francês. 3) Composição em Inglês.

\section{Terceiro Ano:}

1) Filosofia Natural e 'alguns dos principais Experimentos nos Elementos de Química'. 2) 'Um pequeno sistema de Moral (...) concluindo com as Evidências da religião Cristã'. Exercícios Semanais: 1) Dissertações sobre alguns assuntos políticos e comerciais. 2) Traduções Francês-Inglês e Inglês-Francês. ${ }^{24}$

Entre 1757 e 1782, ingressaram na Academia de Warrington cerca de 400 estudantes, provenientes dos mais diferentes pontos da Inglaterra, mas, em sua maioria, das regiões do Norte. Embora tivesse seus objetivos mais diretamente vinculados à formação dos jovens Dissidentes e à preparação dos ministros religiosos Presbiterianos, a academia estava aberta ao público em geral, chegando a receber, inclusive, jovens oriundos de famílias Anglicanas entediadas com o conservadorismo do sistema educacional oficial, constituindo-se, por isso, numa das primeiras e mais inovadoras public schools (escolas públicas) da Inglaterra. ${ }^{25}$

Entre os mais famosos e brilhantes alunos da Academia de Warrington, estiveram: Thomas Percival, médico famoso que foi o primeiro presidente da Literary and Philosophical Society of Manchester (Sociedade Literária e Filosófica de Manchester), fundada em 1781 naquela cidade; William Turner, ministro religioso de Newcastle e professor visitante do Manchester College-York (sucessor da Manchester Academy), que escreveu uma primeira história de Warrington; Thomas Potter, grande comerciante de Man- 
chester; Matthew Nicholson, grande comerciante de Liverpool; William Bancroft, proprietário de uma fábrica de seda em Stockport; Snowden White, médico de Nothingham e um dos maiores defensores da liberdade civil e religiosa para os Não-Conformistas ingleses; John Milnes, grande comerciante em West Ridind e em todo o Yorkshire; Joseph Robinson, grande banqueiro de Manchester; Samuel Crompton, grande banqueiro em Derby e York; John Prior Estlin, eminente religioso NãoConformista; Richard e Benjamin Heywood, filhos do tesoureiro, Arthur Heywood, que sucederam o pai à frente dos negócios comerciais e bancários da família, em Liverpool; Benjamin Vaugham, advogado famoso que chegou a ser membro do parlamento e era filho de Samuel Vaugham, um importante comerciante das "Índias Ocidentais"; George Willoughby, 17\%. Barão de Parham, residente nas cercanias de Rivington (Lancashire), filho do lorde Hugh Willoughby, que foi presidente da academia; Samuel Heywood, eminente advogado de Liverpool e defensor famoso da liberdade civil e religiosa para os Não-Conformistas; o Quaker Samuel Galton Junior, grande comerciante e industrial de Birmingham, membro da $L u$ nar Society (Sociedade Lunar) desta cidade; Samuel Shore, importante militante da causa da liberdade civil e religiosa dos Não-Conformistas, que chegou a ser diretor do Manchester College-York; John Goodricke, matemático e astrônomo famoso, residente em York; e Thomas R. Malthus, o famoso economista político, residente em Cookham. ${ }^{26}$

A Academia de Warrington funcionou até 1783 , quando, em função dos sérios problemas disciplinares de seus alunos, das suas dificuldades financeiras e de uma administração pouco eficiente, não houve o ingresso de novos alunos oriundos da Comunidade Dissidente, cujos pais se sentiam inseguros em colocar seus filhos numa instituição de ensino que vivia uma situação de crise. Naquele ano, o corpo docente da academia se dissolveu e, embora tenham se dado algumas tentativas de revitalização da instituição, ela fechou suas portas definitivamente em 1786, no mesmo ano em que a Comunidade Dissidente criou uma nova instituição de ensino na cidade de Manchester, que se tornou herdeira direta da biblioteca e de toda a tradição de ensino de Warrington, utilizando-se, inclusive, do mesmo Plano de Estudos desta instituição, embora claramente vinculada à corrente teológica Unitária - que afirmava a existência de um Deus Unitário, no melhor estilo da Religião Natural e Racional da Filosofia das Luzes -, e apresentava uma linha de ruptura com a Tradição Presbiteriana. Em 1786, um outro estabelecimento de ensino também foi fundado pelos Unitários em Hackney (Hackney Academy), lo- 
calidade próxima de Londres, que, além dos equipamentos científicos, também herdou a filosofia educacional de Warrington. Entretanto, a Academia de Hackney não conseguiu sobreviver ao clima de perseguição aos Unitários e adeptos do Liberalismo Radical, estabelecido após as King and God Riots, e fechou suas portas em 1794.

A Academia de Manchester sobreviveu a este clima e ainda procurou afirmar enfaticamente o princípio da não-imposição de qualquer tipo de restrição de credo religioso aos seus professores e alunos, embora também objetivasse a formação de jovens para o ministério religioso Unitário. Um folheto de divulgação da academia, de 22 de fevereiro de 1786, em que era anunciada a abertura da nova instituição de ensino, explicitava o princípio da liberdade religiosa, e oferecia ao público um completo "curso de educação liberal”:

Uma reunião muito respeitável de Cavalheiros foi realizada neste dia 22 de fevereiro de 1786, quando foi unanimemente acordado, após a devida deliberação, que uma Academia devia ser estabelecida em Manchester, sob um plano para fornecer um completo e sistemático Curso de Educação para Religiosos, e instruções preparatórias para as Outras Profissões Eruditas, como também para a Vida Civil e Comercial. Esta Instituição estará aberta para jovens de todos os credos religiosos, e não será deles exigido nenhuma prova ou confissão de fé. ${ }^{27}$

$\mathrm{Na}$ realidade, a Academia de Manchester tinha profundas ligações com a Capela de Cross Street (Cross Street Chapel), que era uma importante congregação dos Dissidentes Racionais Unitários da cidade, sendo vinculados a esta congregação quase todos os subscritores (trustees) e os membros do Conselho Diretor da instituição, que era presidido pelo dr. Thomas Percival. Os dois primeiros tutores da academia (nomeados pelo Conselho Diretor), Thomas Barnes e Ralph Harrison, também eram ministros da Capela de Cross Street. Todavia, mantendo a coerência com seus princípios fundadores, a academia empregou o Anglicano Charles Sanders, como tutor em Letras Clássicas, e o Quaker John Dalton, como tutor em Filosofia Natural e Matemática.

Nos seus primeiros momentos, a Academia de Manchester teve uma participação direta na vida política e cultural da cidade, refletindo o ideário do radicalismo Unitário na defesa dos princípios da liberdade e tolerância religiosa, e em importantes campanhas de reforma social e pela abolição do tráfico de escravos africanos. O presidente da academia, Thomas Percival, e o seu primeiro tutor principal, Thomas Barnes, também 
tinham participado, em 1781, da fundação da Literary and Pbilosophical Society of Manchester, que manteve uma estreita relação com a academia durante o período em que ela funcionou na cidade. Inclusive, aos alunos mais antigos - os senior academics - era permitido assistir às sessões da sociedade e às discussões travadas pelos seus membros.

Embora conservando o Plano de Estudos de Warrington, com um "curso especial" de três anos para os "leigos" e um outro curso de cinco anos para a formação dos ministros religiosos, a Academia de Manchester desenvolveu um vínculo muito maior com o mundo dos negócios da já maior cidade industrial da Inglaterra, procurando inclusive ampliar o horizonte cultural dos futuros homens ligados à indústria, ao comércio e às finanças em geral, que obviamente optavam pelo primeiro curso de três anos. Isto se refletia na maior ênfase que as aulas de Comércio, Filosofia Natural e Ciências possuíam no conjunto das disciplinas oferecidas, sem que, no entanto, a formação moral e religiosa dos estudantes leigos fosse relegada a um segundo plano. $\mathrm{O}$ próprio Thomas Barnes foi encarregado das aulas de Comércio, assim como da disciplina de Teologia. Esta maior preferência dos alunos da academia pelo "curso especial" se refletia nos próprios registros da instituição que, entre 1786 e 1797, recebeu 135 es196 tudantes (quase todos de Manchester), dos quais apenas 20 concluíram o curso para a formação de religiosos.

Todavia, apesar da grande reputação que a Academia de Manchester obteve num curto espaço de funcionamento, esta instituição foi obrigada a fechar suas portas em 1803, em virtude de alguns sérios problemas, como a insuficiência dos fundos de financiamento, a indisciplina dos estudantes e a mudança freqüente no quadro de mal remunerados professores. Estes problemas foram agravados pela perseguição que os Unitários sofreram depois das King and God Riots, situação esta que ainda persistia no início do século XIX em virtude do acirramento da Guerra contra a França Napoleônica, e muito contribuiu para provocar a transferência da instituição Unitária de ensino para a cidade de York, em 1803.

Com a mudança para a bucólica York, a instituição chegou inclusive a mudar de nome para Manchester College (Colégio de Manchester), verificando-se também uma completa reformulação do seu quadro de professores, permanecendo apenas George Walker, um dos últimos tutores da fase anterior. Em York, o tutor principal foi Charles Wellbeloved (ministro da congregação Unitária da Saint Saviourgate Chapel, que adotou o mesmo "encargo solene" que o dr. John Taylor utilizava para divulgar, entre os alunos da Warrington Academy, os princípios da liberdade religio- 
sa, da liberdade de pensamento, da valorização da razão e da igualdade de direitos).

O Manchester College-York procurou manter a tradição de ensino das Academias de Warrington e Manchester, tal como apresentava um dos seus panfletos de divulgação, referindo-se aos princípios de "educação liberal para a juventude em geral sem nenhuma distinção de confissão partidária ou religiosa, isenta de qualquer credo político ou subscrição doutrinária”. Esta nova instituição, além de um “curso de instrução para o Ministério Cristão” de cinco anos, ainda se comprometia a manter um plano de estudos para estudantes leigos, com três anos de duração, cujo objetivo maior era "(...) conduzir aqueles que estavam destinados às outras profissões eruditas através de um curso apropriado de estudos preparatórios; ou para capacitar os que estão destinados para a vida comercial a sustentar com a maior respeitabilidade a reputação do comerciante britânico". ${ }^{28}$

Todavia, este compromisso era apenas formal, pois fora do ambiente da maior cidade industrial inglesa, o Manchester College-York substituiu a perspectiva de um ensino prático, associado às necessidades da indústria, do comércio e das finanças, por uma outra perspectiva vinculada às novas descobertas científicas nos campos da Geologia, Botânica e Arqueologia, que eram áreas de interesse cultivadas pelos tutores da instituição. Além disso, diferentemente das instituições de ensino que lhe antecederam, que possuíam como base de sustentação muito mais a Comunidade Dissidente do norte da Inglaterra, o Manchester College-York tornou-se menos "regionalista", e um número muito mais significativo de estudantes vindos do sul do país passou a fazer parte de seu corpo discente.

\section{NOTAS}

* Este artigo é resultado das pesquisas que venho desenvolvendo, desde 1997, com apoio de Bolsa de Produtividade do CNPq, vinculadas ao projeto "Da 'Machina-Mundi' à 'Machina-Faber': a Concepção Mecanicista de Mundo e as Bases Intelectuais da Revolução Industrial Inglesa”.

${ }^{1}$ Para a elaboração da primeira parte do presente artigo, foi consultada a seguinte bibliografia: ACHESON, R. J. Radical puritans in England: 1550-1660. Londres/Nova York: Longman, 1995; BARNES, Thomas. Discourse delivered at the commencement of the Manchester Academy, September XIV, MDCCLXXXVI. Warrington, W. Eyres, 1786; BLACK, Jeremy e PORTER, Roy (Orgs.). A dictionary of eighteenth-century world history. Oxford: Blackwell Publisher, 1994, especialmente pp. 35, 232-233, 498, 748 e 784-785; BRIGGS, Asa - “Introduction”, em SMITH, Barbara (Org.). Truth, liberty, religion. Essays celebrating two hundred years of Manchester College. Oxford: Manchester College, 1986, pp. XI-XVII; HILL, Christopher. The world turned upside down: radical ideas during the English Revolution. Londres: Penguin Books, 1985; 
e Reformation to industrial revolution. Londres: Penguin Books, 1983; LANGFORD, Paul e HARVIE, Christopher. The eighteenth century and the age of industry. The Oxford History of Britain. Oxford: Oxford University Press, 1984; LANGFORD, Paul. A polite and commercial people: England 1727-1783. Oxford: Oxford University Press, 1992; MCLACHLAN, Herbert. English education under the Test Acts. Manchester: Chetam Society, 1931; e Warrington Academy: its history and influence. Manchester: Chetam Society, 1943; MILLER, John. The restoration and the England of Charles II. Londres/Nova York: Longman, 1997; e The Glorious Revolution. Londres/Nova York: Longman, 1997; RAYMOND, Jean e PICKSTONE, John. "The Natural Sciences and the learning of English Unitarians: an exploration of the roles of Manchester College", em SMITH - Op. cit., pp. 127-164; SMITH. "Manchester College Oxford. Cronology of antecedents and development, 1786-1986", em SMITH - Op. cit., XIX-XXIV; WATTS, Michael. From Reformation to the French Revolution. Londres: Penguin Books, 1978; WATTS, Ruth. "Manchester College and education, 1786-1853", em SMITH - Op. cit., pp. 79-110; WEBB, R. K. "The Unitarian background”, em SMITH -Op. cit., pp. 1-30.

${ }^{2}$ WATTS. "The Dissenters", em From Reformation to the French Revolution. Op. cit., pp. 267289. Sobre estes números, ver também: WEBB. "The Unitarian background", em SMITH (Org.). Truth, liberty, religion. Essays celebrating two hundred years of Manchester College. Op. cit, pp. 5-6.

${ }^{3}$ Sobre as correntes Presbiterianas e suas relações teológicas, ver: MCLACHLAN. Warrington Academy: its bistory and influence. Op. cit., p. 5; "Manchester College-Oxford. Chronology of antecedents and development, 1786-1986", em SMITH - Op. cit., pp. XIX-XXIV; WEBB

198 - Op. cit., p. 7; e BLACK e PORTER. A dictionary of eighteenth-century world history. Op. cit., pp. 35,498 e 748.

${ }^{4}$ BLACK e PORTER - Op. cit., p. 498.

${ }^{5}$ BARNES, Thomas. Discourse delivered at the commencement of the Manchester Academy, September XIV, MDCCLXXXVI. Warrington, W. Eyres, 1786, pp. 27-28.

${ }^{6}$ BARNES - Op. cit., p. 27; grifos do autor.

${ }^{7}$ RAYMOND e PICKSTONE. "The natural sciences and the learning of the English Unitarians: an exploration of the roles of Manchester College", em SMITH - Op. cit., pp. 129 e 155.

${ }^{8}$ BRIGGS, Asa. "Introduction”, em SMITH - op. cit., p. XIV.

${ }^{9}$ Para a elaboração da segunda parte deste artigo, a bibliografia consultada foi a seguinte: HOBSBAWM, Eric J. A era das revoluções: 1789-1848. Rio de Janeiro: Paz e Terra, 1977. Manchester College. A short history, 1786-1986. Oxford: Manchester College-Oxford, 1990; MCLACHLAN. English education under the Test Acts. Op. cit.; e Warrington Academy: its history and influence. Op. cit; ; RAYMOND, Jean e PICKSTONE, John. "The Natural Sciences and the learning of English Unitarians: an exploration of the roles of Manchester College", em SMITH - Op. cit., pp. 127- 164; TURNER, William. The Warrington Academy: 1757-1786. Warrington: Library and Museum Committee, 1957; WATTS, Ruth. "Manchester College and education, 1786-1853", em SMITH - op. cit., pp. 79-110; e WEBB, R. K. "The Unitarian background”, em SMITH - Op. cit., pp. 1-30.

${ }^{10}$ MCLACHLAN - Warrington Academy .... Op. cit., p. 16. 
${ }^{11}$ RAYMOND e PICKSTONE - op. cit., pp. 154-155..

${ }^{12}$ WATTS - op. cit., p. 85.

${ }^{13}$ MCLACHLAN. Warrington Academy .... Op. cit., p. 22.

${ }^{14}$ HOBSBAWM - op. cit., p. 46.

${ }^{15}$ WATTS - op. cit., pp. 86-87.

${ }^{16}$ TURNER. The Warrington Academy: 1757-1786. op. cit., p. 3. Na realidade, esta publicação trata-se de três artigos escritos por este autor, que foram originalmente publicados no periódico Monthly Repository, Volumes VIII, IX e X, entre 1813 e 1815.

${ }^{17}$ MCLACHLAN. Warrington Academy .... op. cit., p. 11. Ver também: TURNER - op. cit., p. 3; e WEBB - op. cit., p. 9.

${ }^{18}$ WEBB - Op. cit., p. 9.

${ }^{19}$ TURNER. “The Warrington Academy, 1757:1786”, em Monthly Repository, 1814, volume IX, p. 81. Citado por MCLACHLAN. Warrington Academy .... Op. cit., p. 21.

${ }^{20}$ MARTINEAU, James - Essays and addresses, pp. 400-401. Citado por MCLACHLAN Warrington Academy .... Op. cit., p. 21 (ver também p. 22).

${ }^{21}$ Para a elaboração da terceira e última parte do artigo, foi consultada a seguinte bibliografia: BARNES, Thomas. Discourse delivered at the commencement of the Manchester Academy, September XIV, MDCCCLXXXVI. op. cit.; BRIGGS, Asa. "Introduction", em SMITH - op. cit., pp. XI-XVII; CARTER, G. A. - "Introducion”, em TURNER. The Warrington Academy, 17571786. op. cit., pp. I-IV; Manchester College: a short history, 1786-1786. op. cit:; Manchester College: a bicentenary exbibition organized by Manchester College-Oxford ath the Bodleian Library. Oxford: Manchester College-Oxford, 1986; MCLACHLAN. English education under the Test Acts. op. cit:; e Warrington Academy: its history and influence. op. cit.; RAYMOND e PICKSTONE. "The Natural Sciences and the learning of English Unitarians: an exploration of the roles of Manchester College", em SMITH - op. cit., pp. 127-164; SMITH. "Manchester CollegeOxford. Chronology of antecedents and development, 1786-1986", em SMITH - Op. cit., pp. XIX-XXIV; TURNER. The Warrington Acvademy, 1757-1786. op. cit.; WATTS. "Manchester College and education, 1783-1853", em SMITH - op. cit., pp. 79-110; WEBB. "The Unitarian background", em SMITH - op. cit., pp. 1-30; WYKES, David. "Sons and subscribers: lay support and the College, 1786-1840”, em SMITH - op. cit., pp. 31-78.

${ }^{22}$ MACLACHLAN. Warrington Academy .... Op. cit., p. 16.

${ }^{23}$ Citado por TURNER. op. cit., pp. 10-11.

${ }^{24}$ Esta apresentação do Plano de Estudos de Warrington baseia-se na descrição feita por MCLACHLAN. The Warrington Academy .... Op. cit., pp. 40-41.

${ }^{25}$ As public schools da Inglaterra não podem ser confundidas com as "escolas públicas" dos países latinos, que passaram a ser financiadas pelos poderes públicos (Estado). As public schools inglesas, financiadas por comunidades religiosas ou sociedades civis e abertas a um "público" formado por alunos de diversas origens religiosas, diferenciavam-se das private schools (escolas privadas) - que eram praticamente conduzidas por um único professor, seu proprietário, encarregado de todas as disciplinas, ministradas para um grupo reduzido ou específico de alunos - e, a partir do século XIX, das government schools (escolas go- 
vernamentais) - também abertas ao público em geral, mas mantidas exclusivamente pelo Estado.

${ }^{26}$ Estes nomes são citados numa ampla relação elaborada por TURNER. Op. cit., pp. 5179.

27 “Appendix №. 1 - Manchester Academy instituted Febrary XXII, MDCCLXXXVI”, pp. 1-3, em BARNES. Discourse delivered at the commencement of the Manchester Academy, September XIV, MDCCLXXXVI. op. cit.; os grifos estão no documento original.

28 “Manchester College, York. Prospectus, 1817 (nํㅡ)", em Manchester College, 1786-1986. A bicentenary exbibition organized by Manchester College-Oxford at the Bodleian Library. op. cit., p. 8. 